\title{
Nuevos hallazgos de cerámica campaniforme en la provincia de Orense $^{1}$
}

\author{
Carmelo fernandez Ibã̃ez * \\ Fernando del Rio Martínez *
}

\section{INTRODUCCIÓN}

Hoy por hoy en Galicia, los estudios sobre las distintas facetas de la prehistoria resultan aún escasos; por ello, el pretender hablar del campaniforme gallego plantea el problema de la escasez y dispersión de trabajos, sobre todo si lo comparamos con estudios de la misma categoria en áreas limitrofes. Este embrionario estado de la cuestión está básicamente influenciado por la falta de hallazgos de cierta entidad; hasta ahora la aparición de escasos restos, incompletos en su mayor parte, además de la carencia de secuencias estratigráficas, provoca la fuerte incidencia de simples estudios desde el punto decorativo de unos fragmentos de los que la mayoría ni siquiera permite la reconstrucción de sus perfiles completos.

Pese a todo, no podemos ignorar el hecho de que se han realizado esfuerzos, que traducidos en diversos estudios y publicaciones, poco a poco han conseguido arrojar luz sobre la problemática que rodea la cues-

Este estudio fue presentado, como base de la comunicación del mismo título, en el Congreso "Galicia no Contexto Atlántico da Prehistoria" en homenaje a Florentino López Cuevillas en el centenario de su nacimiento, y celebrado en la ciudad de Orense durante el mes de diciembre de 1986. Esperábamos su publicación en las Actas de dicho congreso, no siendo posible la edición de aquéllas. Ésta, además del trámite de devolución del manuscrito, es la única causa de demora sufrida en la publicación del yacimiento y de los materiales ahora presentados. Los autores desean expresar su agradecimiento más sincero, a J. M. Eguileta por su siempre inestimable colaboración.

* Museo Arqueológico Provincial de Orense. 
tión del campaniforme gallego. Algunos - los últimos - son ya producto de excavaciones recientes, en su mayor parte todavia inéditas, que constituyen un punto de partida a tener en cuenta. Desgraciadamente, nosotros no podemos apoyarnos en el caso anterior, sino que nos enfrentamos con un grupo de fragmentos cerámicos procedentes de un hallazgo de superficie, con las inherentes limitaciones que esta circunstancia conlleva. A pesar de ello, decidimos proceder a su estudio y publicación por tratarse de un lote que consideramos interesante y capaz de aportar datos inéditos.

Lamela, yacimiento del que procede la cerámica ahora estudiada, representa el vigésimocuarto emplazamiento campaniforme de los hasta ahora publicados en Galicia, y los hallazgos en él efectuados, elevan a cincuenta y cuatro el número de fragmentos o recipientes de esta categoria cerámica contabilizados en la misma área geográfica ${ }^{2}$.

\section{LAMELA: LOCALIZACIÓN DEL EMPLAZAMIENTO Y ACCESO}

Se ubica el yacimiento en el término municipal de Pereiro de Aguiar, en la parroquia del mismo nombre y en la aldea de Lamela, siendo sus coordenadas, tomadas sobre la hoja n. ${ }^{\circ} 188$, correspondiente a Nogueira de Ramuin, del M.T.N. escala 1:50.000 y edición de 1944, las que siguen:

$$
\begin{aligned}
& 42^{\circ} 20^{\prime} 05^{\prime \prime} \text { Latitud N } \\
& 4^{\circ} 07^{\prime} 33^{\prime \prime} \text { Longitud W }
\end{aligned}
$$

Se accede al lugar desde Orense por medio de la carretera $\mathrm{N}-120$; a $200 \mathrm{~m}$ del cruce de Luintra, en la margen derecha de la carretera se inicia una pequeña pista asfaltada. Siguiendo esta pista, y después de sobrepasar la aldea de Lamela, se eleva una pequeña colina, y concretamente en las cunetas de la mencionada carretera, es donde hizo su aparición la cerámica que ahora presentamos, ya que la obra de aquella sesgó total o parcialmente - aún hoy se desconoce - este yacimiento, hasta entonces desconocido.

El montículo que nos concierne, constituye la divisoria de aguas entre el río Loña, que discurre por su parte norte, y el Barbaña, a través del arroyo de Pazos, por su parte sur. Tanto el Loña como el Barbaña son

Nos gustaria dejar constancia de la desinteresada ayuda brindada por los dibujantes Belén Canal y Sergio Paredes, en la elaboración de los dibujos que ilustran el presente estudio. 
tributarios del Miño. Desde lo alto de la colina donde se ubica el yacimiento, con una altitud de $448 \mathrm{~m}$ sobre el nivel del mar, se domina hacia el naciente la actual Ilanura - antigua cuenca lacustre - de A Rabeda (fig. 1).

\section{CATÁLOGO DESCRIPTIVO DE LOS HALLAZGOS}

1. Fragmento cerámico, con dimensiones de $2,2 \times 4,4 \times 0,6 \mathrm{~cm}$, correspondiente a un recipiente marronáceo realizado a mano, de buena factura y bruñido exterior final. Presenta como decoración una banda de punciones, formando un clásico motivo «pseudoexciso» enmarcado por líneas puntilladas horizontales y paralelas (fig. 2-1).

2. Fragmento de un recipiente con las mismas caracteristicas decorativas que el anterior y con dimensiones de $5,2 \times 3,6 \times 0,7 \mathrm{~cm}$. Bajo los restos de una banda libre de decoración, presenta un paquete de nueve líneas puntilladas paralelas que, a su vez, se superpone a los restos de un motivo "pseudoexciso" (fig. 2-2).

3. Pequeño fragmento de $2,6 \times 3,3 \times 0,6 \mathrm{~cm}$, con decoración marronácea y terminación bruñida, decorado con dos lineas puntilladas, y enmarcadas inferiormente por un motivo ¿cordado? seguido de una zona exenta de decoración (fig. 2-3).

4. Fragmento de cerámica a mano, de confección cuidada y superficie bruñida, sobre la que se han practicado nueve incisiones horizontales y paralelas. Sus dimensiones son $3,9 \times 4 \times 0,8 \mathrm{~cm}$ (fig. 2-4).

5. Pequeño fragmento marronáceo en el que se pueden ver seis líneas incisas horizontales y paralelas. Sus dimensiones son $2,1 \times$ $1,8 \times 0,6 \mathrm{~cm}$ (fig. 2-5).

6. Fragmento cerámico con dimensiones de $4,7 \times 5 \times 0,9 \mathrm{~cm}$ correspondiente a un recipiente sumamente tosco, hecho a mano y con gruesos desgrasantes de cuarzo, asi como fuerte presencia de mica de menores dimensiones y claramente perceptible en su rugosa superficie. Presenta grueso cordón horizontal como decoración plástica (¿de refuerzo?) (fig. 3-1).

7. Maciza orejeta cerámica de prehensión con sección semicircular; aparece dividida por medio de una incisión a lo largo del eje lon- 


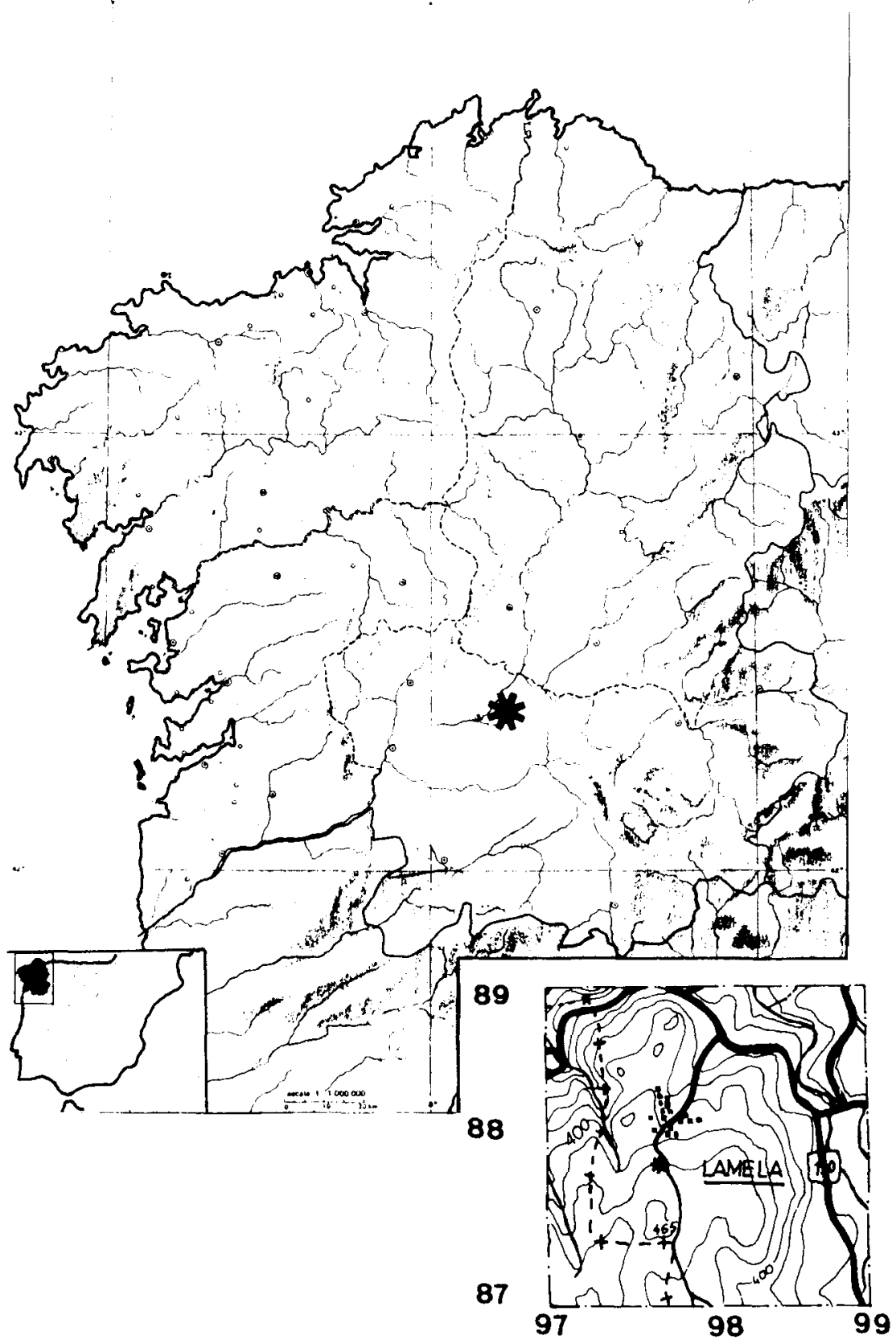

Fig. 1. Localización del yacimiento de Lamela. 


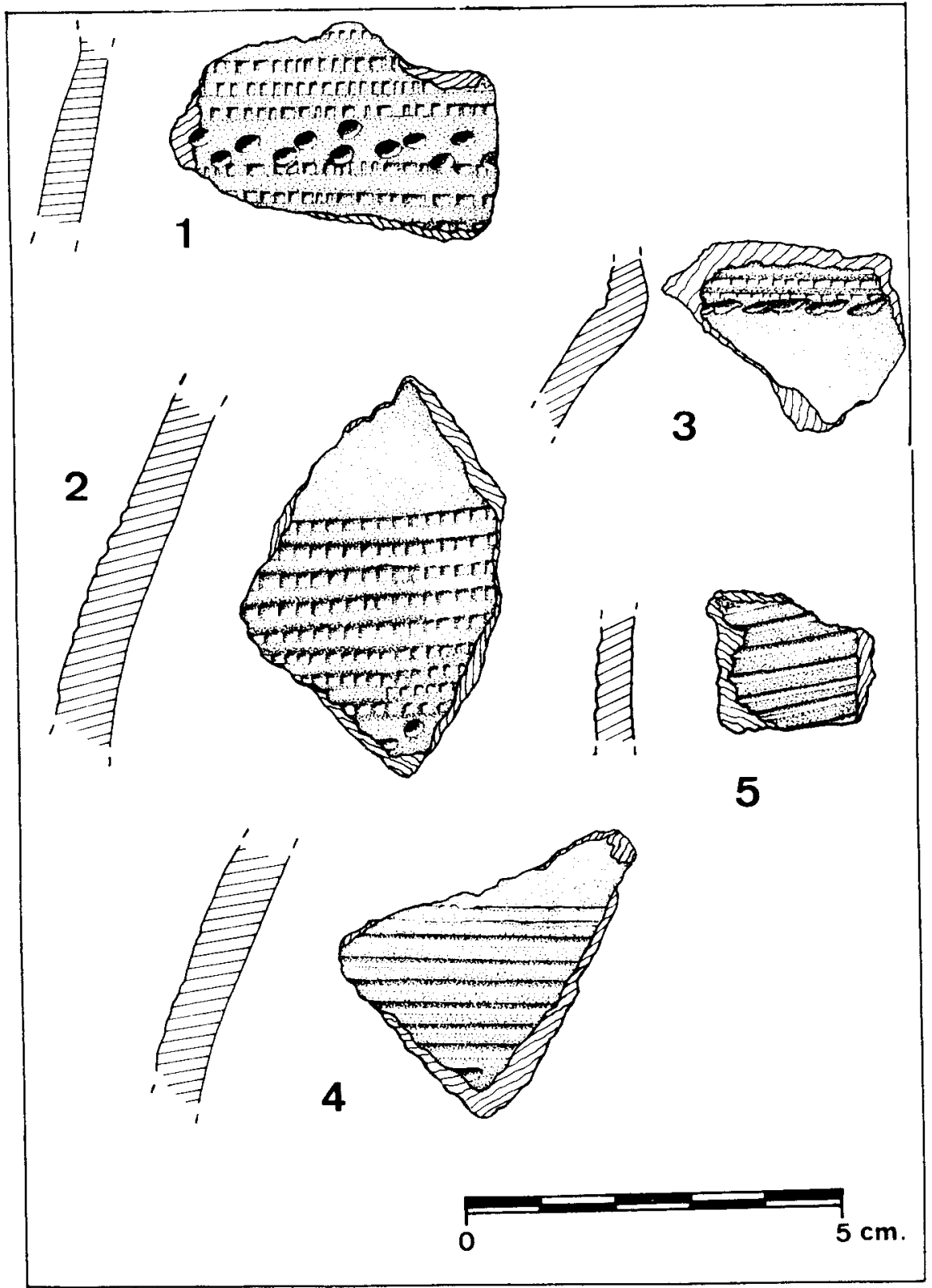

Fig. 2. Cerámica campaniforme de Lamela. 

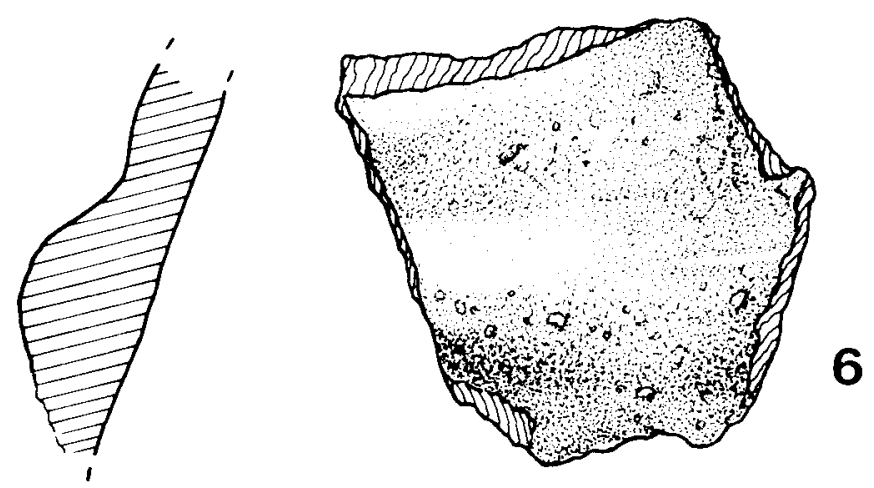

6
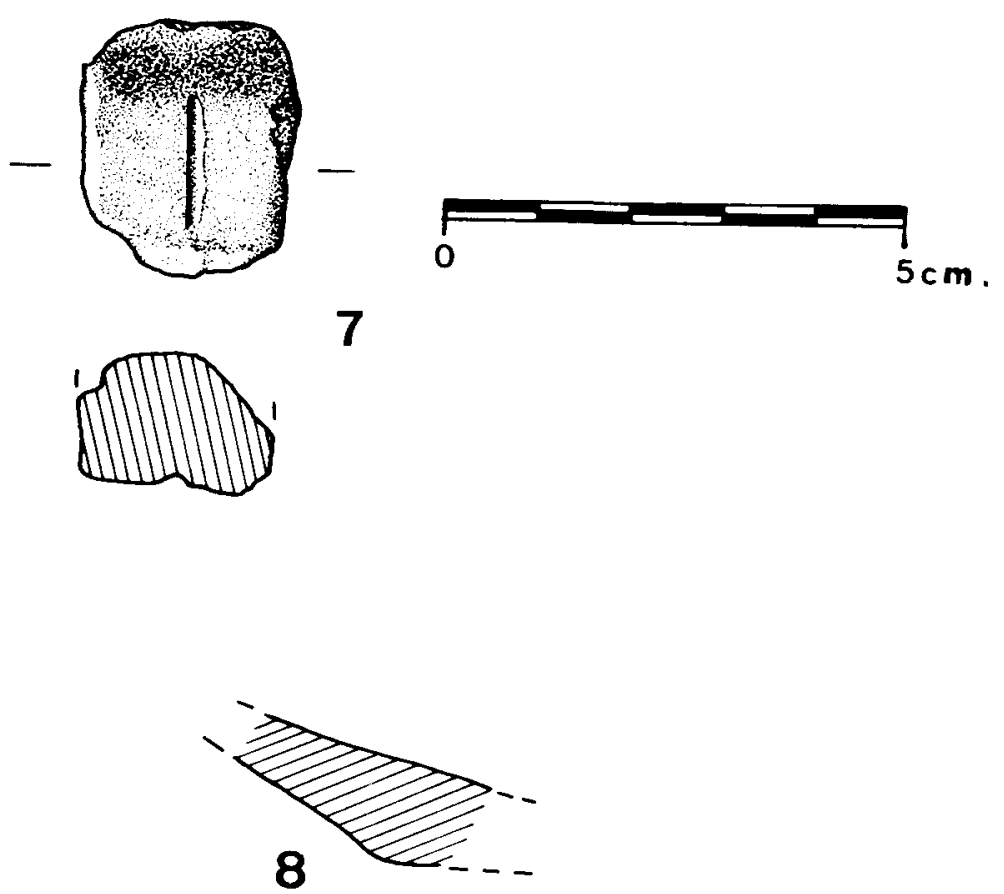

Fig. 3. Algunos fragmentos no decorados. 
gitudinal de la pieza. Tiene unas dimensiones de $2,9 \times 2,3 \times 1,5$ cm (fig. 3-2).

Junto a las piezas descritas, han sido recuperados además otros sesenta fragmentos. En general sus pastas son groseras, en lamentable estado de conservación, evidenciando todas una factura manual con abundante desgrasante cuarcitico y, sobre todo, micáceo. Todos ellos pertenecen a la zona del galbo, excepto la pieza representada en la figura 3-3, que pertenece al fondo de un recipiente. Contamos asimismo, con un prisma de cristal de roca y con una lasca de sílex, escasamente cristalino y color marrón ${ }^{3}$.

\section{ESTUDIO DE LOS MATERIALES}

El estudio del grupo de fragmento cerámicos de Lamela necesariamente ha de abordarse desde el punto de vista decorativo, ya que nada aportan acerca de las formas de los recipientes a los que pertenecieron.

Los dos primeros ejemplares (figs. 2-1 y 2), pertenecen a un mismo estilo decorativo. En la superficie aparecen dos tipos de elementos que si en principio analizamos por separado, posteriormente serán tratados en conjunto. En primer lugar, nos encontramos ante "paquetes" o frisos de lineas paralelas y horizontales utilizando técnica de impresión puntillada mediante peine, decoración conocida como "Variedad Lineal». Esta variante ${ }^{4}$ proporciona una marcada personalidad al campaniforme gallego; F. Criado y J. M. Vázquez relacionan este modelo decorativo hallado en Galicia con el Internacional, que suponen sea sincrónico o, en todo caso, ligeramente posterior a él ${ }^{5}$. De todas formas, debemos decir que esta técnica decorativa no es exclusiva de nuestra zona, sino que se extiende también por otras áreas de la Península ibérica. En ella contamos con algunos ejemplos de frisos de lineas puntilladas, como es el caso de

Todo el material recuperado del yacimiento que aqui se estudia ha sido depositado en el Museo arqueológico de Orense, donde actualmente se expone en una de sus vitrinas.

"No contamos todavia con la certeza de considerar la "Variedad Lineal" como totalmente dependiente del Internacional clásico, o bien que to haya recibido del Cordado tipicamente europeo. Chiado Boado, F.(elipe) y Vazouez Varela, J. M. (anuel), La cerámica campaniforme en Galicia. La Coruña, Cuadernos del Seminario de Sargadelos, n." 42, 1982, pág. 67. Garcia Martinez, M. C.(arlos), "Voz "Campaniforme" ", Gran Enciclopedia Gallega, n." VIII (1974), pág. 108.

5Criado Boado, F. y Vazouez Varela, J. M., Op. cit., pág. 80. 
la cueva de La Tarascona (Segovia), donde hallamos asociaciones triples sobre un vaso con decoración marítima, o bien las que aparecen rellenando y enmarcando espacios entre dientes de lobo en un recipiente puntillado geométrico procedente de la misma cueva ${ }^{6}$. Esta última forma decorativa la volvemos a encontrar en la cazuela de Roupar (Lugo) '

En Portugal, y concretamente en los yacimientos del estuario del Tajo (uno de los focos originarios, según opiniones, de la cerámica campaniforme), son múltiples los hallazgos de puntillado Lineal, desarrollado sobre una variada tipología de cuencos y vasos. Los frisos y franjas, más o menos anchos según el número de lineas puntilladas, acompañan tanto a cuencos de labio engrosado - grupo Palmela - como a los de labio más estrecho y redondeado; en estos cuencos pueden aparecer decoraciones geométricas, también puntilladas, a base de «chevrons» y motivos losángicos, a los que acompaña el puntillado enmarcando o rellenando horizontal $u$ oblicuamente las mismas. Las franjas de lineas puntilladas también pueden aparecer asociadas con lineas de pequeñas impresiones ovales, o grupos de lineas verticales metopadas y asimismo puntilladas. Para corroborar lo dicho, contamos con los yacimientos de Palmela 3 (Setúbal), Alapraia 2 y 4 , y Cabeço de Arruda 2, todos ellos en el territorio de Lisboa.

En el apartado de los vasos, encontramos las lineas puntilladas en grupos dobles y decorando esbeltos recipientes; unas veces presentan perfil en «S» suave, con panza más o menos acusada, mientras que en otros, en el galbo se deja intuir una suave carena (como la que se puede apreciar en uno de los ejemplares de Alapraia). Al igual que lo ya observado en los cuentos, estas lineas enmarcan chevrons puntillados simples o dobles, o también frisos de cortos trazos paralelos y oblicuos de la más clara filiación Internacional; esta aparece en San Martinho de Sintra 1 y 2, Praia das Maças, Casal do Penedo, Serra das Mutelas, San Pedro de Estoril, Belavista y Alapraia 4. En ocasiones, vasos y cuencos con las caracteristicas decorativas que acabamos de definir, han sido hallados asociados en un mismo emplazamiento ${ }^{8}$.

Los anteriores paralelos decorativos parecen evidenciar, una vez más, la fuerte vinculación entre el campaniforme gallego y el de la Extremadura portuguesa ${ }^{9}$.

${ }^{6}$ Delibes, G.(ermán) y Municio, L.(uciano), «Apuntes para el estudio de la secuencia campaniforme en la provincia de Pontevedra", Numantia, $n .{ }^{\circ} 1$ (1981), págs. 37-78, fig. 1-1.

Criado Boado, F. y Vazouez Varela, J. M., Op. cit., pág. 28

${ }^{8}$ LeISNER, G.(eorg) y LEISNER, V.(era), Die Megalithgräber der Iberischen Halbinsel (2 tomos). Berlin 1959-1965.

${ }^{9}$ Criado Boado, F. y Vazouez Varela, J. M., Op. cit., págs. 68-69. 
Pasamos a continuación al estudio de la decoración "pseudoexcisa" que acompaña a la propia "Variedad Lineal» observada en los fragmentos 1 y 2 , ambos con idéntica factura ornamental y probablemente pertenecientes al mismo recipiente cerámico. Esta decoración, alguna vez conocida como "frisos de dientes de lobo a modo de cordones pseudoexcisos", no es nada habitual en la Peninsula lbérica en momentos tempranos. En Galicia encontramos paralelos en el yacimiento de O Fixón (Pontevedra), donde se han encontrado fragmentos informes de clara semejanza con los nuestros. Les acompañan restos cerámicos decorados con técnica puntillada lineal con bandas internacionales y un pequeño fragmento impreso con motivo de "hoja de acacia" asociado al mismo puntillado lineal, cuyos paralelos, según lo publicado, lo sitúan en momentos precampaniformes del estuario del Tajo ${ }^{10}$. No obstante, este mismo motivo aparece, en sentido horizontal enmarcado por profundas líneas incisas, en el yacimiento de San Martinho de Sintra 1 y 2, acompañando a vasos decorados con chevrons, grupos de lineas puntilladas y frisos internacionales ". Procedente de Maus de Salas (Muiños, Orense), contamos en la actualidad con un fragmento de recipiente de similares características, aunque acompañado por muestras impresas a ruedecilla. En Baiao, se recogieron en la cámara del monumento megalítico de Outeiro de Ante ${ }^{12}$, restos de un vaso con idéntica decoración a la nuestra, tres líneas puntilladas enmarcan un friso central con motivos a punzón pseudoexciso.

Especialmente interesante nos resulta uno de los vasos del conjunto campaniforme soriano de Villar de Campo. Dicho recipiente, carente de la zona superior, presenta en el galbo una decoración a base de bandas internacionales y cordones pseudoexcisos mediante hoyitos impresos, 10 que en conjunto no es considerado por Delibes como genuinamente Marítimo. Según el mismo autor, la decoración pseudoexcisa parece provenir del foco bávaro-bohemio (Hungria-Austria-Bohemia-Moravia), es decir,

${ }^{10}$ Garcia Lastra, M.(onserrat), "Ültimas investigaciones de la cerámica campaniforme en la provincia de Pontevedra", /l Coloquio Galaico-Minhoto vol. Il. Santiago 1985, págs. 217227. Garcia Lastra, M.(onserrat), «Primeros resultados de la campaña de excavaciones arqueológicas 1982, en el yacimiento campaniforme de O Fixón (Hio, Cangas de Mozarro, Pontevedra)", Pontevedra Arqueologica, n." 2 (1984), págs. 113-144, pág. 131. Patiño Gomez, R.(amón), "Excavación de un hábitat campaniforme en "O Fixón" ", Revista de Arqueología, ก. 30 (1980), pág. 23.

"Leisner, G. y Leisner, V., Op. cit., lám. 32.

12 Aparecen fragmentos de campaniforme con bandas pseudoexcisas asociados a puntillados; se localizan asimismo en el poblado de Tapado de Caldeira (Baiao). HuET, A. A.(ntonio), "Excavacao da mamoa n." 2 de Outeiro de Ante-Serra da Aboboreira-Baiao", Arqueologia, n. 9 (1984), págs. 22-42, págs. 35 y ss., figs. 12-13. 
del llamado Campaniforme Oriental o Centroeuropeo donde se supone tuvo su origen la pseudoexcisión. Al norte de la línea de los Pirineos, también aparece este motivo decorativo en abundancia; concretamente el llamado Campaniforme Pirenaico y, sobre todo, en su área occidental de dispersión ${ }^{13}$. Todo ello confluye en lo expuesto por Delibes, en el «refujo" de Sangmeister ${ }^{14} \mathrm{y}$, siguiendo a Clarke —como también apunta Delibes-, un "reflujo» europeo en dirección norte-sur, una de cuyas manifestaciones sería el aporte de la «pseudoexcisión» ${ }^{15}$.

La plasmación de la técnica decorativa ahora analizada, resulta sumamente frecuente sobre cerámicas caracterizadoras de un momento avanzado dentro del campaniforme; encontramos varios ejemplos en el estilo Ciempozuelos meseteño, aplicada en cazuelas y vasos decorados con frisos intradecorativos como decoración principal. Es el caso de El Perchel, Piñar Grande y Somaén (Soria), Villabuena del Puente (Zamora), Samboal y Villaverde de Iscar (Segovia) -este último con pervivencias puntilladas-, etc., lo que resulta factible puesto que el estilo tiene raices en el Puntillado geométrico, donde están presentes las pseudoexcisiones (como vimos en el ejemplo expuesto) ${ }^{16}$. Nuevos ejemplos nos ofrece la Meseta Sur - como la cueva de Los Casares (Guadalajara) ${ }^{17}$ - y Andalucia - grupo de Carmona o el Cerro de la Virgen de Orce ${ }^{18}$ - . A lo largo de todo el Levante, contamos con los yacimientos de las cuevas de Sa-

"CAstillo, A.(Iberto) del, “El neoeneolitico», en Historia de España dirigida por Menéndez Pidal, t. I-1. Madrid, Espasa Calpe, 1947, pág. 689, fig. 546. Delibes de CAstro, G.(ermán), "El vaso campaniforme en la meseta norte española", Studia Arqueológica, n. 46. Valladolid 1978, págs. 137-138. DeliBES DE CASTRO, G.(ermán), "Reinterpretación del ajuar campaniforme de Villar del Campo", Celtiberia, n. 56 (1978), págs. 267-286, 278.

14 Delibes, G.(ermán) y Esparza, A.(ngel), “Neolitico y Edad del Bronce» en Historia de Burgos, t. 1. Burgos 1985, pág. 138. SAngmeISTER, E.(duard). "Die datierung des Ruckstrodsder glockenbecher und inner auswirkung auf die chronologie der kupferzeit in Portugal", Paleohistoria, n. ${ }^{\circ}$ XII, págs. 400-401.

is Delibes de Castro, G., "Reinterpretación...", pág. 109. Garcia Martinez, M. C., Op. cit., pág. 109.

16 Barandiaran, I(gnacio), “Revisión estratigráfica de la cueva de la Mora (Somaén, Soria), Noticiario Arqueológico Hispánico. Prehistoria, $n{ }^{\circ} 5$ (1975), págs. 9-71. DeliBts DE CASTRO, G., "El vaso campaniforme...". Delibes, G. y Municio, L., "Apuntes para el estudio...",

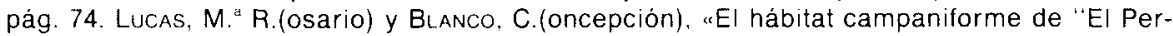
chel" en Arcos del Jalón (Soria)", Noticiario Arqueológico Hispánico, n. 8 (1980), págs. 968.

Barandiaran, 1.(gnacio), "La cueva de los Casares (en Riba de Saelices, Guadalajara)», Excavaciones Arqueológicas en España, n. ${ }^{\circ}$ 76. Madrid, Ministerio de Cultura, 1973, pág. 74 y fig. 20.

${ }^{18}$ Harrison, R. J., Bubner, T. y HibBs, V. A., "The beaker pottery from El Acebuchal, Carmona (prov. Sevilla)", Madrider Miteilungen, n." 17 (1976), págs. 79-141. SCHüle. W.(illiam) y Pellicer, M.(anuel), "El cerro de la Virgen. Orce (Granada)», Excavaciones Arqueológicas en España, n." 46. Madrid, Ministerio de Cultura, 1966 
lamó, Arbolí y Escornalbou (Tarragona), La Alcudia y Promontori (Elche), Covacha Soler (Alicante), Cueva de la Hacha (Almeria), San Antón de Orihuela y Puntal de los Carniceros (Villena) ${ }^{19}$. Quizás sea la pseudoexcisión el origen de los chevrons, repetidamente aplicados en la decoración excisa, y de aparición posterior en la Península lbérica; esto puede soslayarse en uno de los ejemplares de la cueva soriana de Somaén ${ }^{20}$.

Los motivos pseudoexcisos pervivirán en campaniformes tardios, ya en plena Edad del Bronce, acompañando al estilo "Silos", o bien a los hallazgos de Peña Larga, asi como al primer asentamiento del poblado de la Edad del Hierro de La Hoya (ambos en Álava), pertenecientes a la etapa media de la Edad del Bronce ${ }^{21}$.

Volviendo a nuestro yacimiento de Lamela, pasemos ahora al estudio de un fragmento, cuya decoración de líneas puntilladas paralelas, se encuentra enmarcada por una línea de impresiones lanceoladas (fig. 2-3 y lám. (-3). Este motivo decorativo recuerda vivamente, a las impresiones realizadas por medio de "cuerdas" del campaniforme denominado Cordado ("All over corded"). Pero debemos tener en cuenta que tal motivo decorativo está por el momento ausente en Galicia, distribuyéndose en la Peninsula lbérica con relativa densidad por el NE y Pirineos occidentales ${ }^{22}$. Únicamente apuntamos la posibilidad respecto a este pequeño fragmento cerámico - por ello a todas luces insuficiente-, como para realizar una valoración suficientemente reflexiva; máxime, con un motivo decorativo que, cuando menos, recuerda a los cordados.

Poco aportan también, los dos fragmentos con decoración incisa a base de líneas paralelas (fig. 2-4 y 5 , y lám. $1-4$ y 5 ), del yacimiento ahora estudiado. No obstante, es destacable su cuidada elaboración y su superficie bruñida, en contraposición al resto de la ergologia cerámica recuperada.

19 Aparicio Perez, J.(avier), “Departamento de Historia Antigua. Actividades Arqueológicas desde 1979 a 1982», Varia, n. 2 (1983), pág. 408 y figs. 37-38. Castillo, A., Op. cit., págs. 642, 644-645 y figs. 521, 524-525. Ramos FeRnANDez, R.(afael), «Las cerámicas de tipo campaniforme en Elche", Varia, n. 2 (1983), pág. 35. Ramos Fernandez, R.(afael), “Aportaciones estratigráficas para el conocimiento del campaniforme en Elche», en Homenaje al Prts. Martin Almagro Basch, t. Il. Madrid 1983, págs. 7-12. Ramos Fernandez, R.(afael), «Precisiones evolutivas sobre cerámicas de tipo campaniforme". Actas del XVI Congreso Nacional de Arqueologia. Murcia 1982, págs. 113-120.

21 Barandiaran, I., Op. cit. lám. 3.

"Delibes, G. y Municio, L., "Apuntes para el estudio...”, págs. 66, 75 y ss. BaLdeOn İNigo, A.(melia) et alii, Museo de arqueología de Alava. Vitoria, Excma. Diputación Foral de Alava, 1983, s/p. Llanos, A.(rmando), "La Hoya (Laguardia, Alava)», en Arkeoikuska 85. Vitoria 1986. págs. 16-17. 

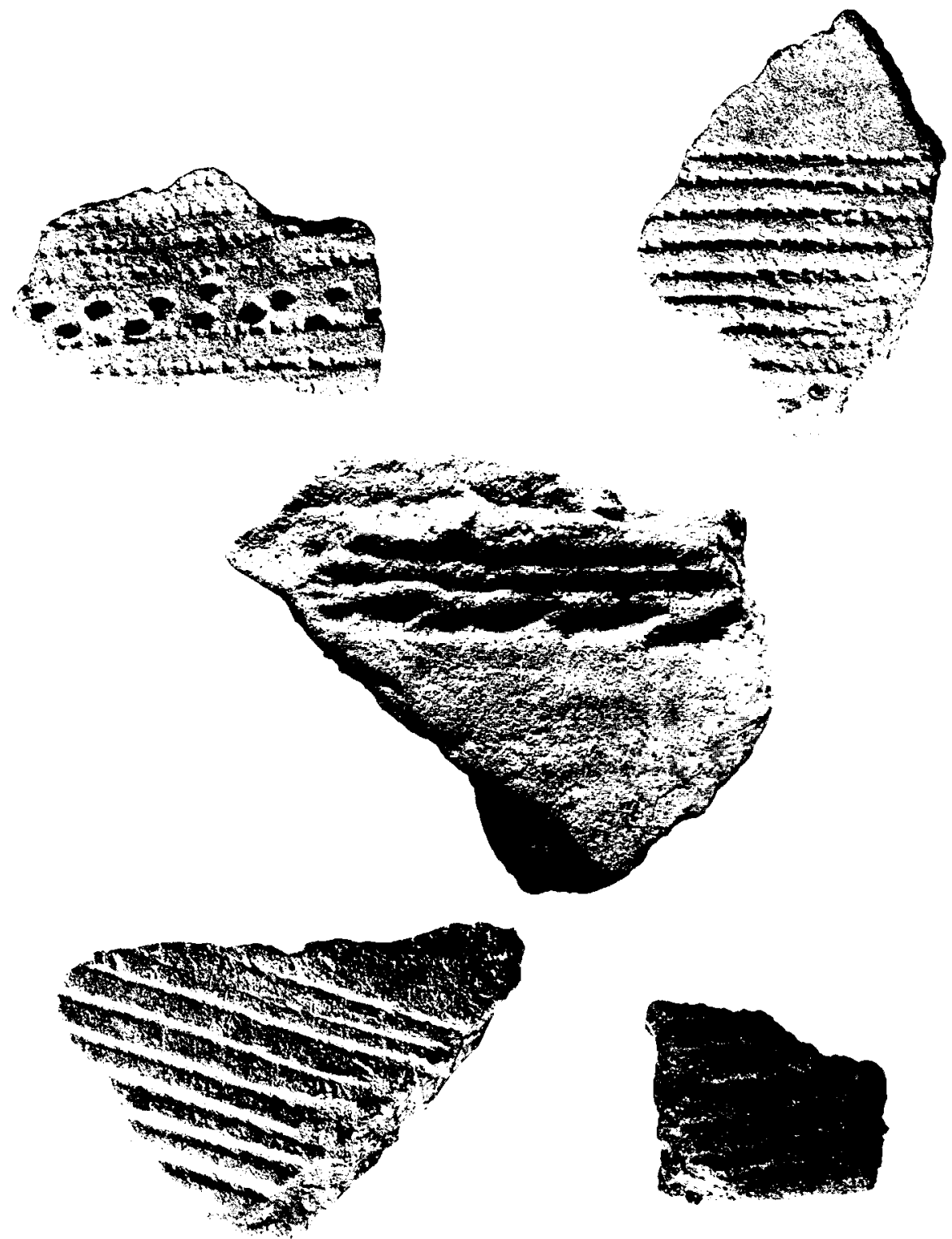

Lám. I. Lamela, Orense. Fragmentos de cerámica campaniforme. 
El resto de los materiales arqueológicos que acompañan a las piezas aqui presentadas (de las que ofrecemos una representación en la fig. 3), forma un grupo de tragmentos cerámicos de los que no se puede sonsacar más información que la de su factura, si bien resulta común la asociación de recipientes lisos, o con algún elemento de refuerzo o de prehensión, en los yacimientos que documentan la presencia de campaniformes. Finalmente, debemos referir la presencia de un gran prisma de cristal de roca, elemento frecuente en el NW en los hallazgos de estas características ${ }^{23}$.

\section{CONCLUSIONES FINALES Y CRONOLOGIA}

Después del anterior análisis, hemos llegado a una serie de conclusiones acerca del grupo cerámico de Lamela. En primer lugar, creemos poder incluir los fragmentos de la fig. 2-1 y 2, dentro de una decoración mixta - o más bien, compuesta- considerada como un elemento más del "reflujo". Esta mezcla de motivos, tan típicamente centroeuropea, penetraria en la Peninsula Ibérica via Rhin-Ródano-Mediodia francés ${ }^{24}$. De una forma general, se ha concretado la llegada europea a suelo peninsular a partir del 2.000 a. C., y con ella, este aún oscuro mundo con que nos encontramos; indudablemente, es mucho más complejo, y sobre el cual tan solo abordamos un aspecto en el presente estudio. Dentro de la referida línea cronológica, y concretamente hacia la primera mitad de este II milenio, se ha llevado el hallazgo de Outeiro de Ante 2; Villar de Campo ${ }^{25}$ abarcaría sin más precisiones el referido milenio. Por último, la muestra tomada del yacimiento pontevedrés de O Fixón datada por medio del $\mathrm{C} 14$, ha dado una fechación de 1980 a. C., lo que corrobora esta aproximación cronológica para nuestro enclave orensano ${ }^{26}$.

Teniendo en cuenta la filiación geográfica de la pseudoexcisión y su posible camino hacia el sur - vide supra-, se acerca también la posi-

\footnotetext{
${ }^{23}$ HaRRison, R.(ichard), The beaker folk. Cooper age archaeology in western Europe. London. Thames and Hudson, pág. 18 y fig. 5 .

"2 Fabregas ValCARCE, R.(amón), "Las prismas de cuarzo en la cultura megalitica del N.O de la Peninsula Ibérica», Brigantium, n. 4 (1983), págs. 7-11.

"Delibes, G. y Municio. L., “Apuntes para el estudio...”. págs. 69-70.

26 Delibes de Castro, G., "Reinterpretación...", pág. 282. Huet, A. A., Op. cit. págs. 35 y Ss.

Garcia Lastra, M. (onserrat), "Aportación a la cronologia campaniforme del noroeste". en Actas del Coloquio de Arqueologia del Noroeste Peninsular, t. I. Porto 1988. Trabalhos de Antropologia y Etnografia. t. XXVIII, n. ${ }^{\text {os }}$ 1-2 (1988), págs. 175-179.
} 


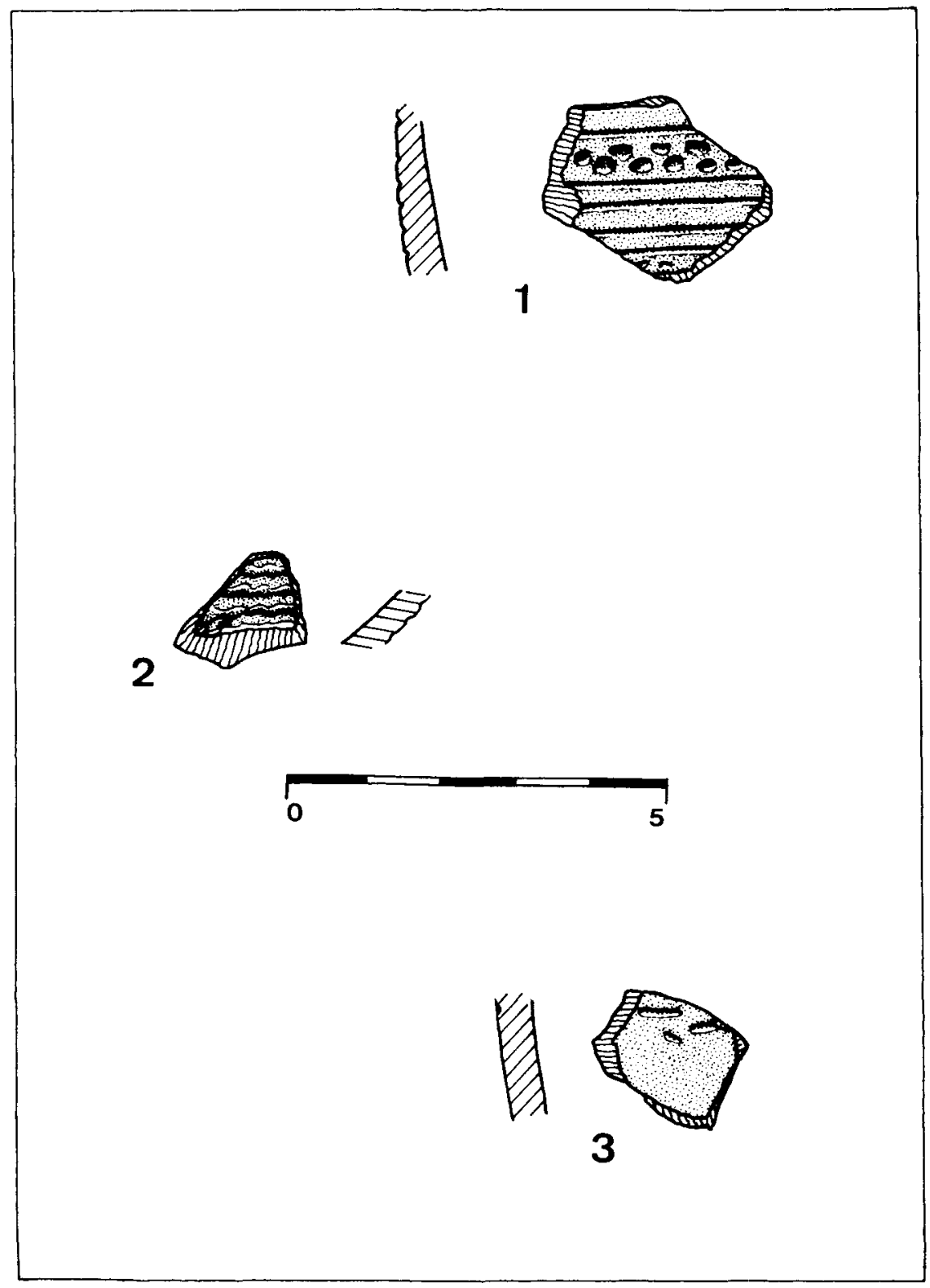

Fig. 4. Lamela. Cerámica con posterioridad al estudio (ver post scriptum). 


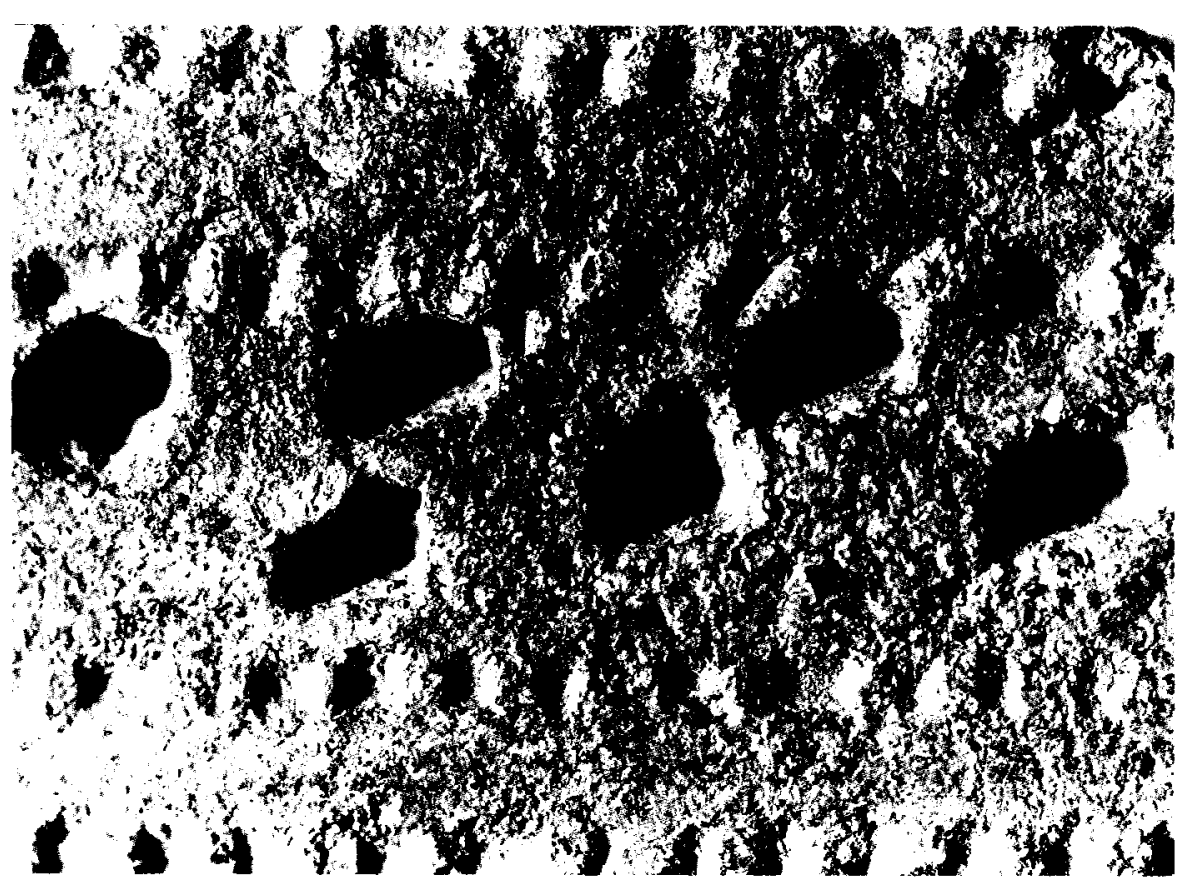

Lám. II. Decoración pseudoexcisa. Detalle. Fragmento n." 1

bilidad de valorar la pieza de la fig. 2-3, como un cordado (?), o bien como una reinterpretación del mismo, pero sin encontrarnos ahora en situación de afirmarlo. No olvidemos el eje Rhin-Ródano, que junto con los Paises Bajos, Islas Británicas y el Mediodia de Francia, ofrecen mayores densidades del campaniforme Cordado (A.O.C.).

Dado el actual estado de la investigación, no podemos saber ni siquiera la forma aproximada, cual fue el modo de penetración de estas corrientes ultrapirenaicas en Galicia. Últimamente los estudios barajan la posibilidad de un acceso a través del valle del rio Duero, aunque tal debate se ve mediatizado por la falta de elementos de juicio cuya solución, creemos pasaria por una todavía más estrecha colaboración de los investigadores de ambos lados de la frontera ibérica.

\section{POST SCRIPTUM}

Con posterioridad a la entrega del estudio para su publicación, han sido recogidos tres fragmentos más de cerámica decorada que las lluvias 


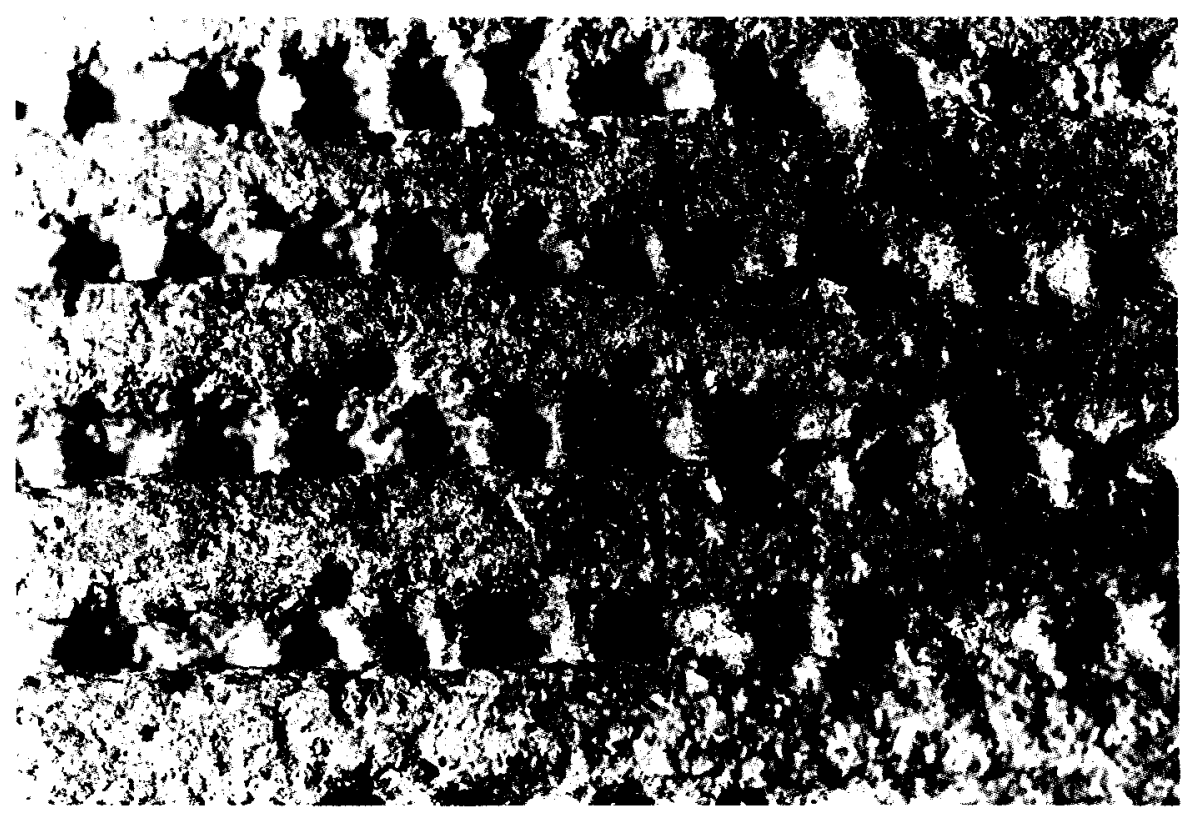

Lam. III. Detalle de la decoración a base de bandas puntilladas. Fragmento n. ${ }^{\circ} 2$.

invernales han sacado a la superficie. Seguidamente pasamos a describirlas, continuando con la numeración iniciada en principio.

9. Fragmento de $3,1 \times 2,5 \times 0,5 \mathrm{~cm}$, de color marrón y confeccionado a mano. En él la decoración alterna bandas horizontales de motivos pseudoexcisos y lineas incisas (fig. 4-1).

10. Pequeño fragmento de $1,8 \times 1,6 \times 0,4 \mathrm{~cm}$ y que podria corresponder a la parte baja del cuerpo de la vasija a la que perteneciese. La decoración, dentro del motivo que ha venido en llamarse "pectiniforme", se desarrolla sobre los restos de cuatro líneas paralelas, horizontales y de aspecto sinuoso (fig. 4-2).

11. Fragmento de panza casi vertical donde se aprecian tres leves incisiones, dos de ellas oblicuas y paralelas. Sus dimensiones máximas son $1,9 \times 1,5 \times 0,5 \mathrm{~cm}$ (fig. $4-3$ ).

Los tres fragmentos cerámicos producto de nuevos hallazgos que aqui incluimos, no varian el estudio ya redactado, aunque lo completan en cuanto ponen de manifiesto la presencia en Lamela de nuevas variedades 


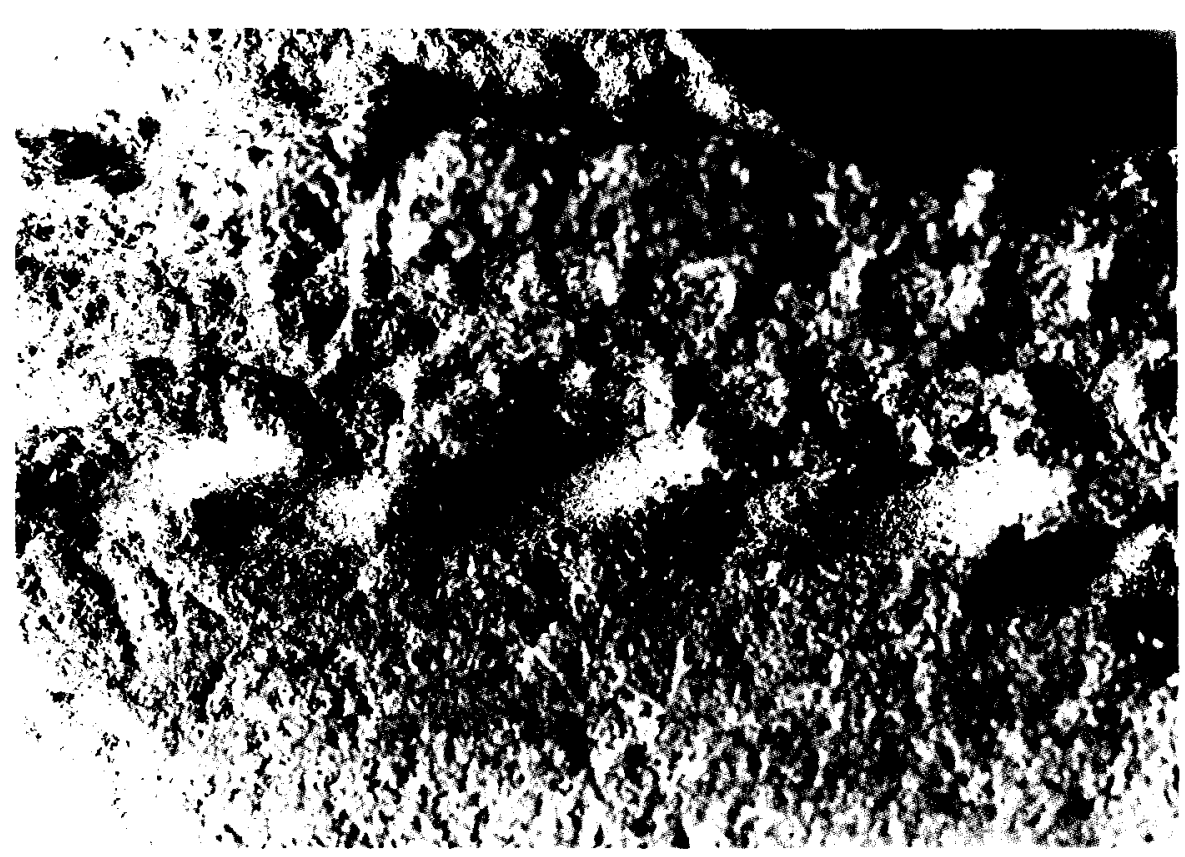

Làm. IV. Ampliación del fragmento n." 3, donde puede apreciarse la decoración de imitación a cordado.

decorativas, asi como manifiestan una nueva composición (pseudoexcisión y líneas).

Tales piezas continúan confirmando la relación de Lamela, en cuanto a motivos decorativos se refiere, con el asentamiento pontevedrés de $O$ Fixón, yacimiento reiteradamente citado en el presente estudio.

\section{RESUMEN}

Se da a conocer un nuevo yacimiento arqueológico en las cercanias de la ciudad de Orense, cuya particularidad es la de haber proporcionado un interesante conjunto de cerámica campaniforme. El análisis y posterior estudio de los diferentes hallazgos (entre los que se encuentra un tipo de decoración pseudocordada), ha permitido llevar al conjunto cerámico a un momento cronológico muy antiguo, y parangonable a otras evidencias - hoy todavia escasas - ya conocidas en Galicia. Posiblemente nos encontramos ante el tan discutido "reflujo"; una de cuyas vias de expansión peninsular pudo haber llegado por la Meseta norte hasta el noroeste. 


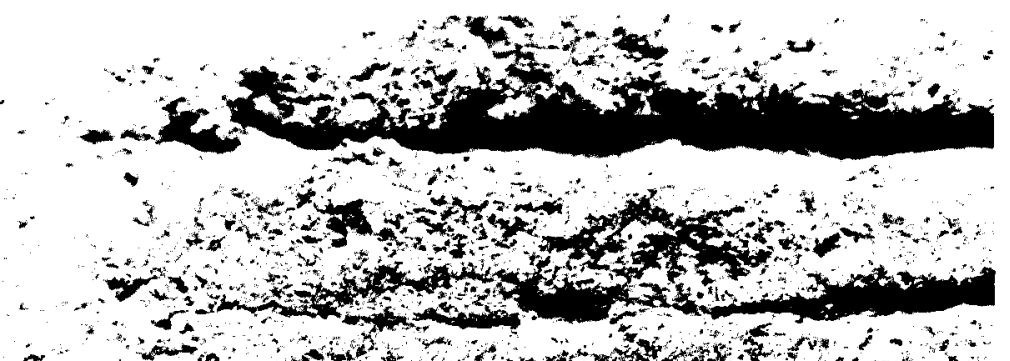

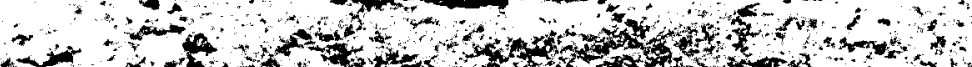

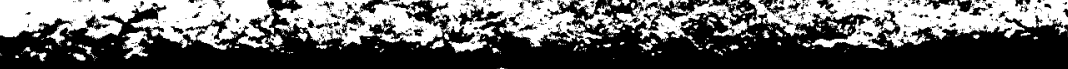

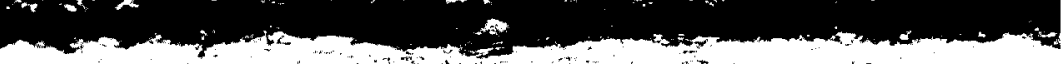

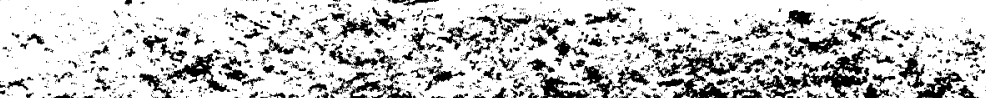

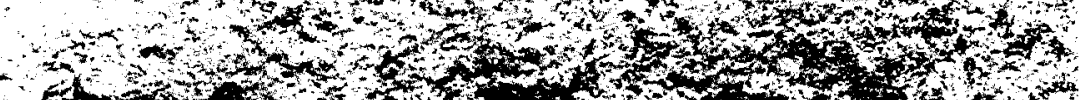

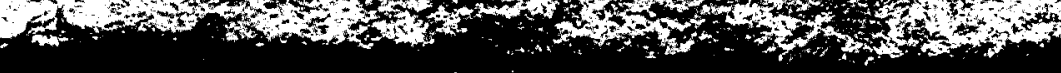

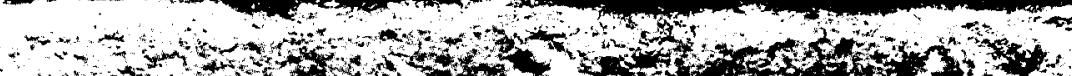

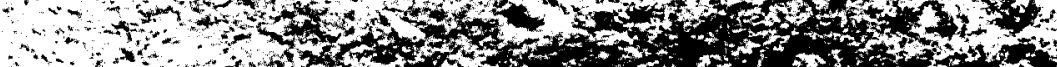

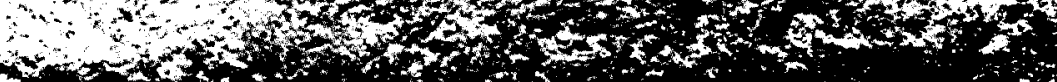
2. I 3

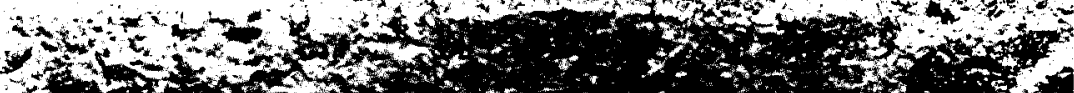

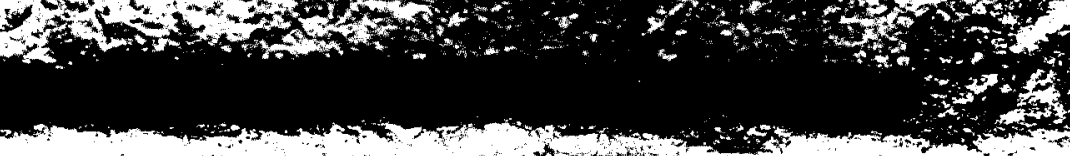

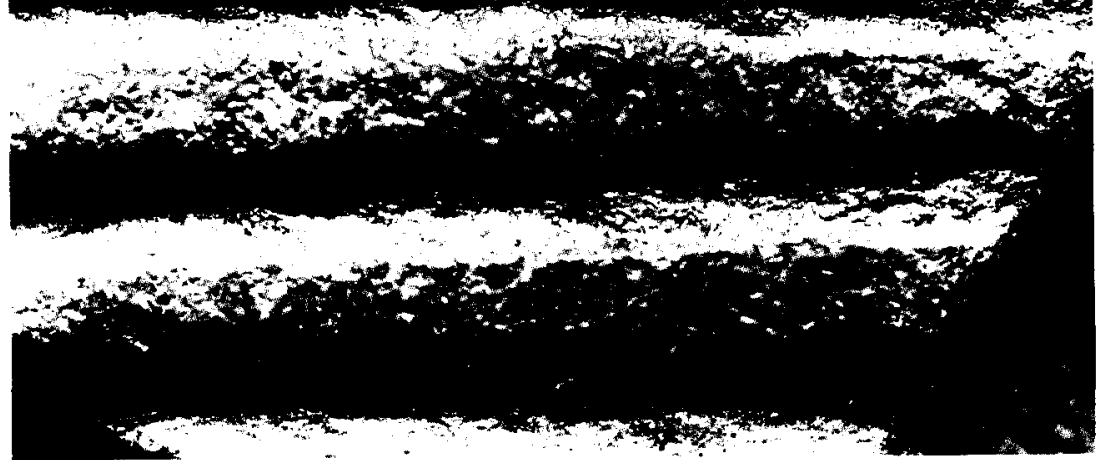

Lám. V. Lineas incisas y paralelas de fragmento n. 5. Ampliación. 


\section{ABSTRACT}

Its to become known a new archaeological deposit nearby the Orsese's town, which furnished an interesting collection of campanulate pottery. The analysis and subsequent study of the different findings (with a type of pseudochordate decoration), it has permited to carry to the collection pottery to a very ancient chronologicla moment, and comparabel to other evidents - very little today - known into Galicia. Perhaps we find in front of so controversial "reflujo"; one of its expansion roads could arrive to hte northwest through the north plateau. 